\title{
Pengaruh Pendidikan Agama Islam Terhadap Akhlak (Perilaku Jujur)
}

\author{
${ }^{1}$ Besse Tanri Akko, ${ }^{2}$ Muhaemin, \\ 1,2Program Studi Pendidikan Agama Islam, FTIK, IAIN Palopo \\ E-mail: besseakko11@gmail.com
}

\begin{abstract}
This study aims to determine the effect of Islamic Education Against Morals (Honest Behavior) of Class X Students in SMA 3 Palopo. This study uses a causal ex-post facto research design with a population of 277 class $X$ students with sampling using a probability sampling technique with a simple random sampling technique established by 73 students. Data collection techniques in this study used observation, documentation and questionnaire techniques. The results of data processing obtained an average score of Islamic education, which is 86.40 with a standard deviation of 7.684 from the ideal score of 100. Similarly, the average score of honest behavior is 88.77 with a standard deviation of 5.760 of the ideal score of 100. The results his research shows that Islamic religious education has a significant influence on the honest behavior of class $X$ students in SMA 3 Palopo with a percentage of $17.2 \%$, while the rest is influenced by other factors. The implication of this research is that if Islamic religious education is taught well it will have a big influence on the formation of the morality of students, the especially honest character which students will actualize in their daily lives both for themselves and for others.
\end{abstract}

Keywords: Islamic Education, Morals (Honest Behavior

\begin{abstract}
Abstrak
Penelitian ini bertujuan mengetahui Pengaruh Pendidikan Agama Islam Terhadap Akhlak (Perilaku Jujur) Siswa Kelas X di SMA Negeri 3 Palopo. Penelitian ini menggunakan desain penelitian ex-post facto yang bersifat kausal dengan jumlah populasi 277 siswa kelas X dengan pengambilan sampel menggunakan teknik probability sampling dengan teknik simple random sampling ditetapkan 73 siswa. Teknik pengumpulan data pada penelitian ini menggunakan teknik observasi, dokumentasi dan angket. Hasil pengolahan data diperoleh skor rata-rata pendidikan Agama Islam, yaitu 86,40 dengan standar deviasi sebesar 7,684 dari skor ideal 100. Demikian halnya skor rata-rata perilaku jujur yaitu 88,77 dengan standar deviasi sebesar 5,760 dari skor ideal 100. Adapun hasil penelitiannya menunjukkan bahwa pendidikan Agama Islam memiliki pengaruh yang signifikan terhadap perilaku jujur siswa kelas X di SMA Negeri 3 Palopo dengan persentase sebesar 17,2\%, sedangkan sisanya dipengaruhi oleh faktor lain. Implikasi penelitian ini yaitu jika Pendidikan Agama Islam diajarkan dengan baik maka akan berpengaruh besar terhadap terbentuknya akhlak peserta didik khususnya akhlak jujur yang akan diaktualisasikan peserta didik dalam kehidupan sehari-hari baik terhadap diri sendiri maupun terhadap orang lain.
\end{abstract}

Kata Kunci : Pendidikan Agama Islam, Akhlak (Perilaku Jujur). 


\section{Pendahuluan}

Salah satu tujuan manusia menempuh pendidikan adalah untuk membentuk pribadi yang lebih baik, khususnya membentuk akhlak yang baik. Hal ini sejalan dengan firman Allah dalam QS. al-Ahzab/33:21

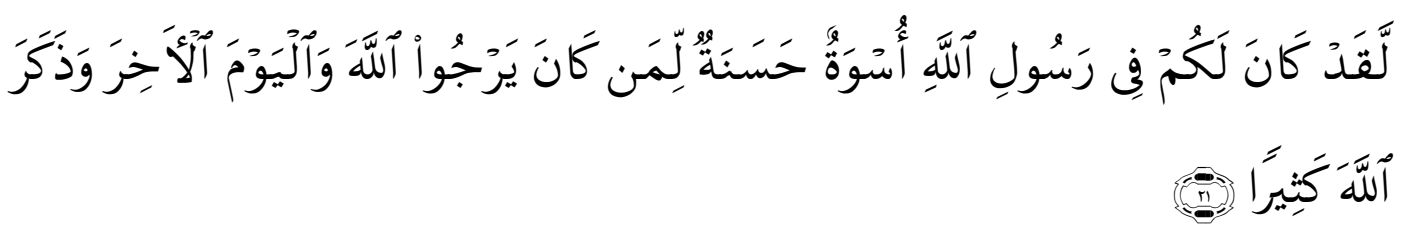

Terjemahnya:

"Sesungguhnya telah ada pada (diri) Rasulullah itu suri teladan yang baik bagimu (yaitu) bagi orang yang mengharap (rahmat) Allah dan (kedatangan) hari kiamat dan Dia banyak menyebut Allah". ${ }^{1}$

Rasullullah adalah suri teladan yang baik, artinya Rasullullah memiliki akhlak yang baik. Sebagai umatnya tentulah kita ingin mencontohnya. Untuk membentuk akhlak yang baik ditempuh dengan jalan pendidikan, sehingga salah satu tujuan pendidikan adalah membentuk akhlak yang baik

Pendidikan adalah usaha sadar dan terencana untuk mewujudkan suasana belajar dan proses pembelajaran agar peserta didik secara aktif mengembangkan potensi dirinya untuk memiliki kekuatan spiritual keagamaan, pengendalian diri, kepribadian, kecerdasan, akhlak mulia serta keterampilan yang diperlukan dirinya, masyarakat, bangsa dan negara.2

Pembentukan akhlak pertama kali didapatkan di lingkungan keluarga, apabila orang tua berhasil menerapkan pendidikan akhlak terhadap anak maka seorang anak akan lebih mudah dibentuk menjadi pribadi yang lebih baik ketika anak memasuki lembaga pendidikan formal. Seperti halnya pendidikan formal dan informal, pendidikan nonformal tak kalah pentingnya sebab lingkungan juga sangat berperan penting terhadap pembentukan sikap

1 Departemen Agama RI., al-Qur'an dan terjemahnya, (Jakarta: Pustaka Al-Kautsar, 2009), h. 420.

${ }^{2}$ Hasbullah, Dasar-Dasar Ilmu Pendidikan, (Jakarta: Rajawali Pers, 2006), h. 4 
dan perilaku seseorang. Apabila suatu lingkungan baik maka akan berpengaruh baik terhadap seseorang. Begitupun sebaliknya, apabila lingkungan buruk maka akan berpengaruh buruk terhadap seseorang.

Lembaga pendidikan merupakan salah satu wadah yang berperan penting dalam membentuk kepribadian, moral dan akhlak siswa. Untuk itu sekolah sangat diharapkan keberhasilannya dalam membentuk kepribadian, akhlak dan moral siswa. Nilai pendidikan yang didapatkan oleh siswa di sekolah harus nampak dalam kehidupan siswa, namun kenyataan tidaklah demikian, karena kurangnya kesadaran terhadap nilai akhlak dan kepribadian siswa sehingga banyak terjadi penyimpangan-penyimpangan yang dilakukan oleh kalangan siswa.

\section{Kerangka Teoretis}

Pendidikan Agama Islam

Pendidikan Agama Islam adalah upaya sadar dan terencana dalam menyiapkan peserta didik untuk mengenal, memahami, menghayati, mengimani, bertakwa, berakhlak mulia, mengamalkan ajaran-ajaran Agama Islam dari sumber utamanya kitab suci al-Quran dan al-Hadits, melalui kegiatan bimbingan, pengajaran latihan, serta penggunaan pengalaman. ${ }^{3}$ Kegiatan bimbingan dapat dilakukan orang tua di rumah dan guru di sekolah. Namun, yang memiliki peran utama dalam bimbingan Agama Islam adalah orang tua sebab anak menghabiskan waktu lebih banyak di rumah bersama dengan orang tua dibanding waktu anak di sekolah orang tua juga dapat memberikan pengajaran latihan dan pembiasaan dengan memberi contoh teladan kepada anak. Contoh pengajaran latihan dan pembiasaan yang diberikan orang tua kepada anak adalah mendirikan salat lima waktu secara berjamaah, puasa wajib ataupun sunnah, bersikap amanah dan lain-lain. Fungsi Pendidikan Agama Islam dijelaskan dalam QS. al-Baqarah/2:151

\footnotetext{
${ }^{3}$ Ramayulis, Metodologi Pendidikan Agama Islam, (Jakarta : Kalam Mulia, 2008), h. 21.
} 


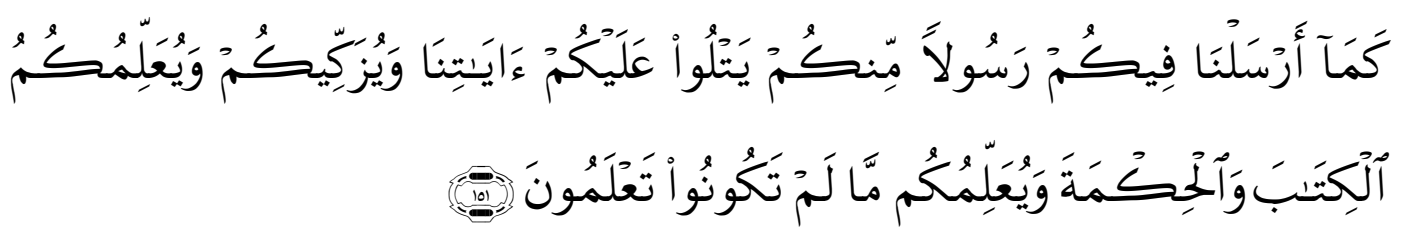

Terjemahnya :

"sebagaimana (kami telah menyempurnakan nikmat Kami kepadamu) Kami telah mengutus kepadamu Rasul diantara kamu yang membacakan ayat-ayat Kami kepada kamu dan mensucikan kamu dan mengajarkan kepadamu Al kitab dan Al-Hikmah, serta mengajarkan kepada kamu apa yang belum kamu ketahui".4

Pendidikan Agama Islam bertujuan meningkatkan keimanan, pemahaman, penghayatan, dan pengamalan peserta didik tentang Agama Islam sehingga menjadi manusia muslim yang beriman dan bertakwa kepada Allah serta berakhlak mulia dalam kehidupan pribadi, bermasyarakat, berbangsa dan bernegara. ${ }^{5}$ Jadi, pendidikan Agama Islam di sekolah memiliki tujuan untuk meningkatkan keimanan dan ketakwaan siswa serta mengamalkan ajaran Islam dalam kehidupan sehari-hari. Pendidikan Agama Islam juga bertujuan memahami ajaran-ajaran Islam secara sederhana dan bersifat menyeluruh sehingga dapat digunakan sebagai pedoman hidup dalam amalan perbuatan baik hubungan dengan Allah, sesama manusia serta dapat membentuk pribadi yang berakhlak mulia sesuai dengan ajaran Islam. ${ }^{6}$

Ruang Lingkup Pendidikan Agama Islam meliputi aspek-aspek sebagai berikut:

1. Al-Qur'an dan hadist

Secara bahasa al-Qur'an adalah "bacaan" sedangkan secara istilah berarti kalam Allah yang merupakan mukjizat yang diturunkan kepada Nabi

4 Departemen Agama RI., al-Qur'an dan terjemahnya, (Jakarta :Pustaka Al-Kautsar, 2009), h. 151.

5 Ibid.

${ }^{6}$ www.pustakaaslikan.blogspot.co.id, diakses tanggal 19 Juni 2017. 
Muhammad melalui perantara Malaikat Jibril yang disampaikan kepada kita secara mutawatir dan membacanya merupakan ibadah.

Adapun hadist secara bahasa adalah "sesuatu yang baru" sedangkan secara istilah hadist adalah seluruh perkataan, perbuatan dan hal ihwal tentang Nabi Muhammad Saw., yang termasuk hal ihwal dalam definsi di atas adalah segala sesuatu yang diriwayatkan dari nabi.

Al-Qur'an dan hadist adalah sumber hukum islam yang menjadi pedoman bagi seluruh umat manusia.

2. Aqidah

Aqidah Islam adalah kepercayaan yang mantap kepada Allah, para malaikat-Nya, kitab-kitab suci-Nya, para rasul-Nya, hari akhir, qadar yang baik dan buruk serta seluruh muatan al-Qur'an dan sunnah berupa pokokpokok agama.

3. Akhlak

Ilmu akhlak adalah ilmu yang menentukan batas antara baik dan buruk, terpuji dan tercela, tentang perkataan dan perbuatan manusia, lahir dan batin.

4. Fiqih

Kata "fiqh" secara etimologis berarti paham yang mendalam. Secara definitif fiqih berarti ilmu tentang hukum-hukum syar'i yang bersifat amaliah yang digali dan ditemukan dari dalil-dalil tafsili. Dengan demikian, secara ringkas dapat dikatakan fiqih adalah dugaan kuat yang dicapai seorang mujtahid dalam usahanya menemukan hukum Allah.

\section{Tarikh dan Kebudayaan Islam}

Tarikh dan kebudayaan Islam meliputi sejarah arab pra-Islam, kebangkitan nabi yang di dalamnya menjelaskan keberadaan nabi sebagai pembawa risalah, pengaruh Islam dikalangan bangsa arab, Khulafaur 
Rasyidin, pergerakan politik dan agama serta berbagai motifnya yang sangat berpengaruh terhadap politik, agama, kesusastraan, kemasyarakatan dan lain-lain. ${ }^{7}$

\section{Akhlak}

Kata "akhlak" dalam kamus Bahasa Arab yaitu خلقy yang artinya tabiat atau budi pekerti. ${ }^{8}$ yang dimaksud akhlak disini ialah bahwa manusia berkelakuan dalam kehidupannya sesuai dengan kemanusiaannya, yaitu kedudukan mulia yang diberikan kepadanya oleh Allah melebihi makhlukmakhluk yang lain, dan ia diangkat sebagai khalifah. ${ }^{9}$ Akhlak merupakan sifat yang sudah melekat pada diri manusia dan sudah merupakan sikap batin yang menyatu dengan kepribadiannya. ${ }^{10}$

Menurut Imam al-Ghazali yang dikutip dalam Mustofa akhlak ialah suatu sifat yang tertanam dalam jiwa yang daripadanya timbul perbuatanperbuatan dengan mudah, dengan tidak memerlukan pertimbangan pikiran (lebih dahulu). ${ }^{11}$ Jadi, perbuatan yang dilakukan tanpa memerlukan pertimbangan pemikiran sebab perbuatan tersebut lahir dari sifat yang telah tertanam dalam jiwa seseorang sehingga perbuatan tersebut menjadi kebiasaan.

Menyinggung tentang akhlak dan hubungannya dengan pendidikan, maka tidaklah sulit untuk menemukan korelasi antara keduanya. Semua aspek pendidikan dimaksudkan untuk tercapainya tujuan pendidikan. Sementara itu, tujuan pendidikan dalam perspektif Islam banyak berhubungan dengan kualitas manusia yang berakhlak. ${ }^{12}$

${ }^{7}$ Zacky Muzakkil, www.blogspot.com/2010/10blog.post.html?m=1, diakses tanggal O2 Februari 2017

8 Tashih, KH. Ali Ma'shum, KH. Zainal Abidin Munawwir, Kamus Al-Munawir ArabIndonesia Terlengkap, (Surabaya : Pustaka Progressif, 1984), h. 364.

${ }^{9}$ Hasan langgulung, Asas-Asas Pendidikan Islam, (Jakarta : Pustaka Al Husna Baru, 2003), h. 113.

10 M. Arif R, Esensi Pendidikan Islam : Memahami Akhlak Sebagai Esensi Materi Pendidikan Islam, (Palopo : Lembaga Penerbitan Kampus (LDK) STAIN Palopo,2011), h. 143.

${ }^{11}$ A. Mustofa, Akhlak Tasawuf, (Bandung : Pustaka Setia, 1999), h. 12.

12 M. Arif R, op. cit., h. 145. 


\section{Perilaku Jujur}

Dalam Bahasa Arab, kata jujur semakna dengan "as-sidqu” atau "siddiq" yang berarti benar, nyata atau berkata benar. Secara istilah, jujur atau as-sidqu bermakna kesesuaian antara ucapan dan perbuatan, kesesuaian antara informasi dan kenyataan, ketegasan dan kemantapan hati dan sesuatu yang baik yang tidak dicampuri kedustaan. ${ }^{13}$

Shidq (jujur) adalah kesesuaian antara suara hati dengan ucapan, sehingga jika salah satu syarat itu hilang maka tidaklah dikatakan sebagai kejujuran yang sempurna. ${ }^{14}$ Jujur adalah mengakui, berkata atau pun memberi suatu informasi yang sesuai dengan apa yang benar-benar terjadi atau kenyataan. Dari segi bahasa, jujur dapat disebut juga sebagai antonim atau pun lawan kata bohong yang artinya adalah berkata ataupun memberi informasi yang tidak sesuai dengan kebenaran. ${ }^{15}$

Kejujuran merupakan pondasi bagi akhlak sekaligus pangkal dari semua akhlak, karenanya terlihat seorang yang jujur selal dipenuhi dengan keutamaan dan akhlak yang luhur, ia selalu terus terang dan tidak hipokrit ,qona'ah, penuh kasih sayang, selalu berbuat baik, sabar, menjaga kehormatan diri, rendah hati, transparan, adil dan tidak melakukan penipuan, tidak berkhianat serta tidak melakukan tipu daya, sedang orang yang terbiasa berdusta, jelas sikapnya tentu akan sebaliknya. ${ }^{16}$ Jujur adalah salah satu akhlak terpuji yang harus dimiliki oleh setiap orang sebagaimana yang telah dicontohkan oleh manusia paling mulia yakni Nabi Muhammad saw.,

${ }^{13}$ Anonim,www.bacaanmadani.com/2016/11pengertian-jujur-dan-macammacamnya.html? $\mathrm{m}=1$, diakses tanggal 25 Januari 2017

${ }^{14}$ Sulaiman, Shidiq dan Kadzib, (Jakarta : Darus Sunnah Press,2004), h. 9

${ }^{15}$ Anonim, https://pengertiandefinisi.com/pengertian-jujur-dan-macam-macamsifat-jujur-dalam-agama-islam/, diakses tanggal 20 Januari 2017

${ }^{16}$ Sulaiman, op. cit., h. 15 
Sabda Rasulullah saw., :

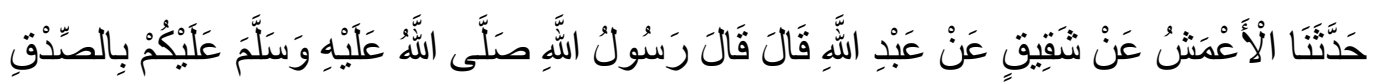

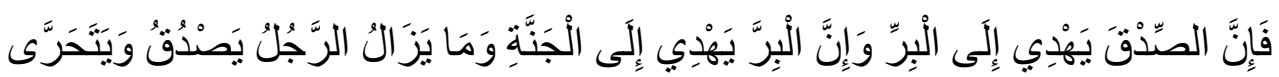

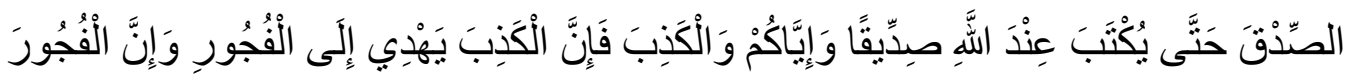

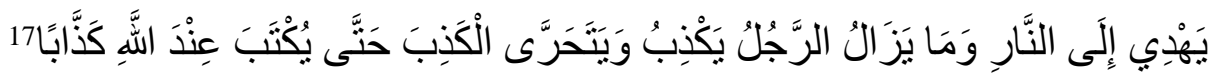

Artinya:

"Telah menceritakan kepada kami Al A'masy; Demikian juga diriwayatkan dari jalur lainnya, Dan telah menceritakan kepada kami Abu Kuraib; Telah menceritakan kepada kami Abu Mu'awiyah; Telah menceritakan kepada kami Al A'masy dari Syaqiq dari 'Abdullah dia berkata; Rasulullah shallallahu 'alaihi wasallam bersabda: 'Kalian harus berlaku jujur, karena kejujuran itu akan membimbing kepada kebaikan. Dan kebaikan itu akan membimbing ke surga. Seseorang yang senantiasa berlaku jujur dan memelihara kejujuran, maka ia akan dicatat sebagai orang yang jujur di sisi Allah. Dan hindarilah dusta, karena kedustaan itu akan menggiring kepada kejahatan dan kejahatan itu akan menjerumuskan ke neraka. Seseorang yang senantiasa berdusta dan memelihara kedustaan, maka ia akan dicatat sebagai pendusta di sisi Allah."'18

Hadist di atas menjelaskan betapa pentingnya berkata jujur sebab berkata jujur membawa kebaikan. Sebaliknya, berkata dusta akan membawa kepada kejahatan.

Sabda Rasulullah saw.:

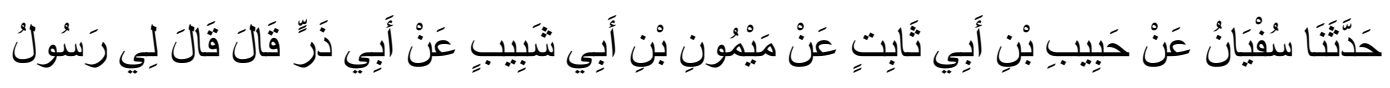

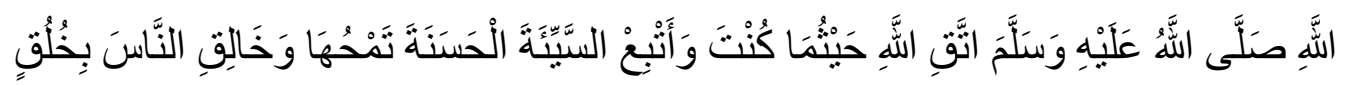

17 Abu Husain Muslim bin Hajjaj Alqusyairi Annaisaburi, "Shahih Muslim", (BairutLibanon : Darul Fikri, 1993), h. 534.

18 Imam Abu Husein Muslim bin Hajjaj Al Qusyairy, "Shahih Muslim", diterjemahkan oleh Adib Bisri Musthofa dengan judul Shahih Muslim, (Semarang : CV Asy Syifa, 1993), h.534.

${ }^{19}$ Abu Isa Muhammad bin Isa bin Saurah, "Sunan Tirmidzi”, (Bairut-Libanon : Darul Fikri, 1994),h.398. 
Artinya:

telah menceritakakan kepada kami Sufyan dari Habib bin Abu Tsabit dari Maimun bin Abu Syabib dari Abu Dzar ia berkata; Rasulullah shallallahu 'alaihi wasallam pernah bersabda kepadaku: "Bertakwalah kamu kepada Allah dimana saja kamu berada dan ikutilah setiap keburukan dengan kebaikan yang dapat menghapuskannya, serta pergauilah manusia dengan akhlak yang baik."20

Lama setelah Rasulullah saw.,. Meninggal dunia, orang bertanya kepada Aisyah: "Bagaimana akhlak Rasulullah?" Aisyah berkata "Akhlak beliau adalah al-Qur'an”. Ketika orang mendesaknya: “Apa yang dimaksud akhlak Rasulullah adalah al-Qur'an?" Aisyah memberikan contoh: "Tidakkah kamu membaca Surah

al-Mu'minun?" mungkin karena dalam Surah al-Mu'minun karakteristik seorang mukmin secara jelas digambarkan dengan akhlaknya. ${ }^{21}$ Sebagai umat Nabi Muhammad, sudah sepatutnya kita mencontohi akhlak beliau di dalam kehidupan kita. Sepanjang masa ia memperlihatkan watak yang murni dan sifat yang begitu dapat dipercaya sehingga orang-orang sekelilingnya menamakannya orang yang dapat dipercaya atau al-Amin. ${ }^{22}$

Dalam Agama Islam, setidaknya dikenal lima jenis sifat jujur yang harus dimiliki, yaitu:

1. Shidq al-Qalbi merupakan sifat jujur yang penerapannya ada pada niat seorang manusia.

2. Shidq al-Hadits merupakan sifat jujur yang penerapannya ada pada perkataan yang diucapkan oleh manusia.

3. Shidq al-Amal merupakan sifat jujur yang penerapannya ada pada aktivitas dan perbuatan manusia.

${ }^{20}$ Abu Isa Muhammad bin Isa bin Saurah, "Sunan at- Tirmidzi", diterjemahkan oleh Moh. Zuhri dkk dengan judul Sunan at- Tirmidzi, (Semarang : CV Asy Syifa, 1992), h.502.

${ }^{21}$ Jalaluddin Rakhmat, Dahulukan Akhlak di Atas Fiqih, (Bandung : Muthahhari Press, 2007), h.143.

22 Seyyed Hossein Nasr, "Muhammad Man Of Allah"; diterjemahkan oleh R. Soejadi Djojopranoto dengan judul : Kekasih Allah Muhammad, (Ed. 1. Cet. 3; Jakarta : Srigunting, 2002), h.6. 
4. Shidq al-Wa'd merupakan sifat jujur yang penerapannya ada pada janji yang diucapkan oleh manusia.

5. Shidq al-Hal merupakan sifat jujur yang penerapannya ada pada kenyataan yang terjadi dalam hidup manusia. ${ }^{23}$

Sifat jujur adalah hal yang sangat penting untuk dimiliki oleh setiap orang dalam aspek kehidupan, baik itu dalam kehidupan rumah tangga, perniagaan dan dalam kehidupan masyarakat. Sebab dengan sifat jujur yang dimiliki oleh seseorang akan membuatnya dicintainya dan dihormati oleh orang di sekitarnya.

Kejujuran memiliki beragam bentuk diantaranya :

1. Jujur dalam berbicara yaitu, jika seorang muslim berbicara, dia hanya berbicara dengan kebenaran dan kejujuran, jika memberitahukan, dia hanya memberitahukan peristiwa yang benar-benar terjadi;

2. Benar dalam bertekad yaitu, jika seorang muslim bertekad untuk mengerjakan sesuatu yang pantas untuk dikerjakan maka dia tidak akan ragu-ragu mengerjakannya tanpa menoleh pada hal lain sampai selesai dari pekerjaannya;

3. Jujur dalam bermuamalah yaitu, bermuamalah dengan jujur, sedikitpun tidak berlaku curang, tidak menipu, tidak memalsu dan tidak memperdayakan orang lain;

4. Benar dalam berjanji yaitu, jika seorang muslim berjanji kepada seseorang maka dia menepati janjinya karena ingkar janji termasuk tanda-tanda kemunafikan;

5. Jujur dalam penampilan yaitu, seorang muslim tidak berpenampilan dengan penampilan yang bukan aslinya dan tidak menampakkan sesuatu yang berbeda dengan batinnya dan tidak mengenakan pakaian

${ }^{23}$ Anonim, https://pengertiandefinisi.com/pengertian-jujur-dan-macam-macamsifat-jujur-dalam-agama-islam/, diakses tanggal 8 Juli 2017. 
kepalsuan, tidak riya dan tidak memaksakan diri dengan sesuatu yang bukan miliknya. $^{24}$

Hendaklah setiap muslim memiliki sifat jujur dan senantiasa berlaku jujur dalam keadaan apapun sebab sifat jujur adalah akhlak yang luhur dan mulia sebagaimana yang telah dicontohkan oleh Nabi Muhammad saw.

Oleh karena itu, pangkal semua amalan hati adalah kejujuran dan sebaliknya pangkal riya, ujub, sombong, membanggakan diri, menolak kebaikan, jahat, malas, pengecut, hina dan lain-lain adalah dusta. ${ }^{25}$ Dengan kata lain amalan yang baik datangnya dari kejujuran dan amalan atau sifat yang buruk datangnya dari dusta.

\section{Metode dan Hasil Penelitian}

Penelitian ini adalah merupakan penelitian ex post facto yang mencari tau pengaruh pengaruh pendidikan Agama Islam terhadap akhlak (perilaku jujur) siswa kelas X di SMA Negeri 3 Palopo. SMA ini merupakan salah satu sekolah pavorit dan unggulan di kota palopo. Populasi penelitian sebanyak 277 siswa dengan mengambil sampel 73 siswa dengan teknik Simple Random Sampling. Instrumen dan teknik pengumpulan penelitian ini adalah angket, Prestasi belajar Pendidikan Agma Islam yang diambil melalui dokumentasi. Teknik analisis data yang digunakan analisis kualitatif dan analisis kuantitatif.

Hasil analisis statistika yang berkaitan dengan skor variabel Pendidikan Agama Islam diperoleh gambaran karakteristik distribusi skor Pendidikan Agama Islam. Hal ini digambarkan pada tabel berikut ini:

24 Mahmud Al-Misri, Hiduplah Bersama Orang-Orang Jujur, (Solo : Pustaka Arafah, 2008, h. 117-118)

25 Ibid.,h. 284. 
Tabel 4.11

Statistik Deskriptif Pendidikan Agama Islam

\begin{tabular}{ll}
\hline \multicolumn{1}{c}{ Statistik } & \multicolumn{1}{c}{ Nilai Statistik } \\
\hline Ukuran Sampel & 73 \\
Rata-rata & 86,40 \\
Nilai Tengah & 87,00 \\
Standar Deviasi & 7,684 \\
Varians & 59,048 \\
Rentang Skor & 40 \\
Nilai Terendah & 57 \\
Nilai Tertinggi & 97 \\
\hline
\end{tabular}

Jika skor Pendidikan Agama Islam dikelompokkan kedalam lima kategori maka diperoleh tabel distribusi frekuensi dan persentase Pendidikan Agama Islam. Jadi, skor Pendidikan Agama Islam dikelompokkan berdasarkan banyaknya item dari setiap kategori sehingga hasil pengukurannya dianalisis melalui metode statistik yang kemudian diberikan interpretasi secara kualitatif. ${ }^{26}$ Adapun tabel distribusi frekuensi dan persentase Pendidikan Agama Islam adalah sebagai berikut:

Tabel 4.12

Perolehan Persentase Kategorisasi Pendidikan Agama Islam

\begin{tabular}{|c|c|c|c|}
\hline Skor & Kategori & Frekuensi & Persentase (\%) \\
\hline $51-60$ & Sangat Buruk & 2 & $3 \%$ \\
\hline $61-70$ & Kurang Baik & 1 & $1 \%$ \\
\hline $71-80$ & Cukup Baik & 8 & $11 \%$ \\
\hline $81-90$ & Baik & 41 & $56 \%$ \\
\hline $91-100$ & Sangat Baik & 21 & $29 \%$ \\
\hline & Jumlah & 73 & $100 \%$ \\
\hline
\end{tabular}

Sumber: Hasil Analisis Data Primer Penelitian yang diolah, Thn 2017

Berdasarkan tabel 4.11 dan 4.12 di atas dapat disimpulkan bahwa Pendidikan Agama Islam termasuk dalam kategori baik dengan frekuensi 41 orang dan hasil persentase 56\%. Adapun skor rata-rata yaitu 86,40.

\footnotetext{
${ }^{26}$ Anas Sudijono, Pengantar Evaluasi Pendidikan ( Jakarta: Raja Grafindo Persada, 2006) h. 35 .
} 
Tingginya Pendidikan Agama Islam dipengaruhi oleh respon siswa terhadap angket yang diberikan.

Hasil analisis statistika deskriptif berkaitan dengan skor variabel perilaku jujur diperoleh gambaran karakteristik distribusi skor perilaku jujur yang. Hal ini digambarkan pada tabel berikut ini:

Tabel 4.13

\begin{tabular}{ll}
\multicolumn{2}{l}{ Statistik Deskriptif Perilaku Jujur } \\
\hline Statistik & Nilai Statistik \\
\hline Ukuran Sampel & 73 \\
Rata-rata & 88,77 \\
Nilai Tengah & 90,00 \\
Standar Deviasi & 5,760 \\
Varians & 33,181 \\
Rentang Skor & 30 \\
Nilai Terendah & 70 \\
Nilai Tertinggi & 100 \\
\hline
\end{tabular}

Jika skor perilaku jujur dikelompokkan ke dalam lima kategori diperoleh tabel distribusi frekuensi dan persentase perilaku jujur sebagai berikut :

Tabel 4.14

Perolehan Persentase Kategorisasi perilaku jujur

\begin{tabular}{llcc}
\hline Skor & Kategori & Frekuensi & Persentase (\%) \\
\hline $51-60$ & Kurang Sekali & 0 & $0 \%$ \\
$61-70$ & Kurang & 1 & $1 \%$ \\
$71-80$ & Cukup & 7 & $10 \%$ \\
$81-90$ & Baik & 40 & $55 \%$ \\
$91-100$ & Baik Sekali & 25 & $34 \%$ \\
\hline & Jumlah & 73 & $100 \%$
\end{tabular}

Sumber: Hasil Analisis Data Primer Penelitian yang diolah, Thn 2017

Berdasarkan tabel 4.13 dan 4.14 di atas dapat disimpulkan bahwa tingkat perilaku jujur di SMA Negeri 3 Palopo termasuk dalam kategori baik dengan frekuensi 40 orang dan presentase 55\%. Adapun skor rata-ratanya 
yaitu 88,77. Tingginya tingkat perilaku jujur dipengaruhi oleh respon siswa terhadap angket yang diberikan.

Analisis korelasi sederhana terhadap Pendidikan Agama Islam (X) dan perilaku jujur (Y) menunjukkan koefisien korelasi $r_{\mathrm{y}}$ sebesar 0,414 . Hasil pengujian keberartian koefisien korelasi dengan menggunakan uji t diperoleh bahwa thitung $=3,837$ signifikan pada taraf nyata 0,000. Hal ini berarti bahwa korelasi antara aspek Pendidikan Agama Islam (X) dan perilaku jujur (Y) signifikan.

Analisis regresi sederhana terhadap data skor perilaku jujur (Y) dan data skor Pendidikan Agama Islam (X) menghasilkan konstanta" $\alpha$ " sebesar 61.927 dan koefisien regresi "b" sebesar 0,311 sehingga persamaan regresinya yaitu: $\overline{\mathrm{y}}=61.927+0,311$. Pengujian keberartian antara aspek Pendidikan Agama Islam (X) dan perilaku jujur (Y) seperti yang terdapat pada lampiran dapat disimpulkan bahwa regresi dengan persamaan $\overline{\mathrm{y}}=$ $61.927+0,311 x$. signifikan dan linear.

Persamaan regresi $\overline{\mathrm{y}}=61.927+0,311 x$. menunjukkan bahwa setiap kenaikan satu skor pada aspek Pendidikan Agama Islam (X) menyebabkan kenaikan sebesar 0,311, skor perilaku jujur (Y) pada konstanta sebesar 61.927.

Pengaruh positif antara aspek Pendidikan Agama Islam (X) dan perilaku jujur (Y) didukung oleh koefisien determinasi sebesar 0, 172. Hal ini berarti bahwa 17,2\% variasi yang terjadi pada variabel perilaku jujur (Y) dapat dijelaskan oleh variasi aspek Pendidikan Agama Islam (X) melalui persamaan regresi $\overline{\mathrm{y}}=61.927+0,311$.

\section{Penutup}

Hasil penelitian menunjukkan bahwa Pendidikan Agama Islam memiliki pengaruh yang signifikan terhadap akhlak (perilaku jujur) siswa kelas X di SMA Negeri 3 Palopo dengan persentase sebesar 17,2\%. Hal ini sesuai dengan hipotesis yang dirumuskan yakni ada pengaruh signifikan Pendidikan 
Agama Islam terhadap akhlak (perilaku jujur) siswa kelas X di SMA Negeri 3 Palopo.

Pendidikan Agama Islam perlu mendapatkan perhatian terutama dari pihak keluarga dan sekolah karena sangat berpengaruh terhadap akhlak (perilaku jujur) siswa. Selain itu, guru dalam melaksanakan tugasnya sebagai pendidik hendaknya tidak mengabaikan penanaman nilai kejujuran dalam proses pembelajaran dengan cara mengintegrasikan nilai kejujuran ke dalam proses pembelajaran yang akan dilakukan.

\section{Daftar Pustaka}

Abu Husain Muslim bin Hajjaj Alqusyairi Annaisaburi, "Shahih Muslim", Bairut-Libanon: Darul Fikri, 1993

Abu Isa Muhammad bin Isa bin Saurah, "Sunan at- Tirmidzi", diterjemahkan oleh Moh. Zuhri dkk dengan judul Sunan at- Tirmidzi, Semarang: CV Asy Syifa, 1992.

Abu Isa Muhammad bin Isa bin Saurah, "Sunan Tirmidzi". Bairut-Libanon: Darul Fikri, 1994

Al-Misri, Mahmud. Hiduplah Bersama Orang-Orang Jujur, Solo: Pustaka Arafah, 2008

Departemen Agama RI. al-Qur'an dan terjemahnya. Jakarta: Pustaka AlKautsar, 2009

Hasbullah. Dasar-Dasar Ilmu Pendidikan. Jakarta: Rajawali Pers, 2006.

Imam Abu Husein Muslim bin Hajjaj Al Qusyairy, "Shahih Muslim", diterjemahkan oleh Adib Bisri Musthofa dengan judul Shahih Muslim, Semarang : CV Asy Syifa, 1993.

Langgulung, Hasan. Asas-Asas Pendidikan Islam. Jakarta: Pustaka Al Husna Baru, 2003.

M. Arif R, Esensi Pendidikan Islam: Memahami Akhlak Sebagai Esensi Materi Pendidikan Islam, Palopo : Lembaga Penerbitan Kampus (LDK) STAIN Palopo,2011.

Nasr, Seyyed Hossein. "Muhammad Man of Allah"; diterjemahkan oleh R.Djojopranoto, Soejadi. Kekasih Allah Muhammad, Ed. 1. Cet. 3; Jakarta: Srigunting, 2002. 
Rakhmat, Jalaluddin. Dahulukan Akhlak di Atas Fiqih. Bandung: Muthahhari Press, 2007.

Ramayulis. Metodologi Pendidikan Agama Islam. Jakarta: Kalam Mulia, 2008.

Sudijono, Anas. Pengantar Evaluasi Pendidikan Jakarta: Raja Grafindo Persada, 2006.

Sulaiman, Shidiq dan Kadzib, Jakarta: Darus Sunnah Press,2004

Tashih, KH. Ali Ma'shum, KH. Zainal Abidin Munawwir, Kamus Al-Munawir Arab-Indonesia Terlengkap. Surabaya: Pustaka Progresif, 1984. 